\title{
Solitary sclerotic fibroma on the thigh
}

\author{
Ji Hoon Kim ${ }^{1}$, \\ Chi Ho Shin', \\ Dong Chul Kim ${ }^{1}$, \\ So Ya Paik', \\ Chong Kun Lee ${ }^{1}$ \\ Departments of ${ }^{1}$ Plastic and \\ Reconstructive Surgery and ${ }^{2}$ Pathology, \\ Bundang Jesaeng Hospital, Seongnam, \\ Korea
}

\begin{abstract}
Sclerotic fibroma is a rare fibrous tumor of the skin associated with Cowden's disease. In 1989, Rapini described sclerotic fibroma without Cowden's disease as solitary sclerotic fibroma of the skin. It is a solid, well-circumscribed, slow-growing nodular tumor and it looks similar to a keloid scar. Consequently, it is extremely difficult to make a differential diagnosis of solitary sclerotic fibroma with keloid scar based on clinical findings only. The authors report a case of solitary sclerotic fibroma arising at the left lateral thigh of a 25-year-old man.
\end{abstract}

Keywords: Diagnosis, differential / Fibroma / Keloid / Skin neoplasms

\section{INTRODUCTION}

Sclerotic fibroma of the skin is a rare fibrous tumor of the skin. The two types of sclerotic fibromas are known as multiple lesions associated with Cowden's disease [1], and solitary lesions without Cowden's disease [2]. Solitary sclerotic fibroma is rare and extremely difficult to diagnose based on clinical findings only because these findings are nonspecific and similar to keloid scar. We have experienced a case of solitary sclerotic fibroma at the left lateral thigh area in a 25-year-old man, which the clinical findings were similar to a keloid scar. Therefore, a careful approach to clinical and histological examination is required for patients with these similar lesions.

\section{CASE REPORT}

A 25-year-old man presented to our hospital with a mass on the left thigh, which he had for 2 years. Clinical assessments at the first visit revealed a firm, fixed, well-circumscribed, pinkish polypoid tumor measuring about $3 \times 3 \times 1.5 \mathrm{~cm}$ (Fig. 1 ). He was in the habit of picking pieces of the small mass from time to time. There was no specific family history or past medical his-

\section{Correspondence: Ji Hoon Kim}

Department of Plastic and Reconstructive Surgery, Bundang Jesaeng Hospital,

20 Seohyeon-ro 180beon-gil, Bundang-gu, Seongnam 13590, Korea

E-mail: freetime33@naver.com

Received July 18, 2020 / Revised August 15, 2020 / Accepted October 6, 2020 tory related to solitary sclerotic fibroma and physical examination showed neither pain nor tenderness. Under general anesthesia, the authors performed a surgical excision and the defect was covered with a split thickness skin graft without radiation therapy (Fig. 2).

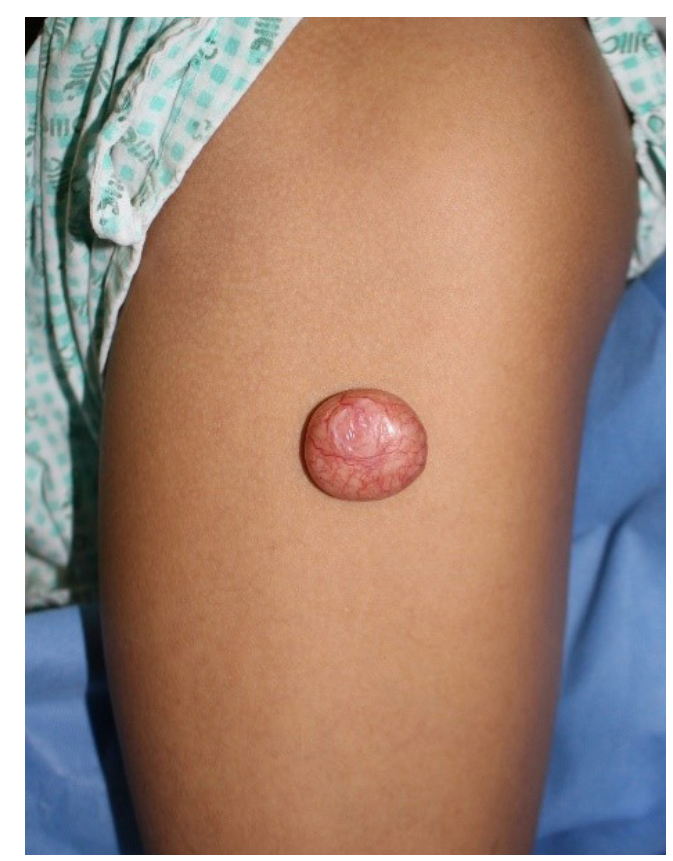

Fig. 1. Preoperative photograph showing a $3 \times 3 \times 1.5 \mathrm{~cm}$ sized mass on left lateral thigh area. 


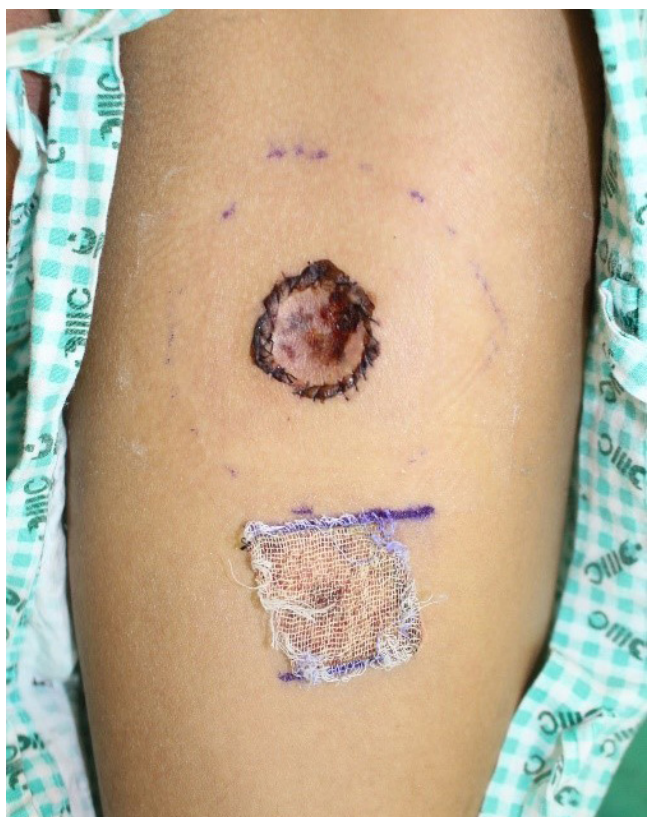

Fig. 2. Postoperative photograph 10 days after surgery.

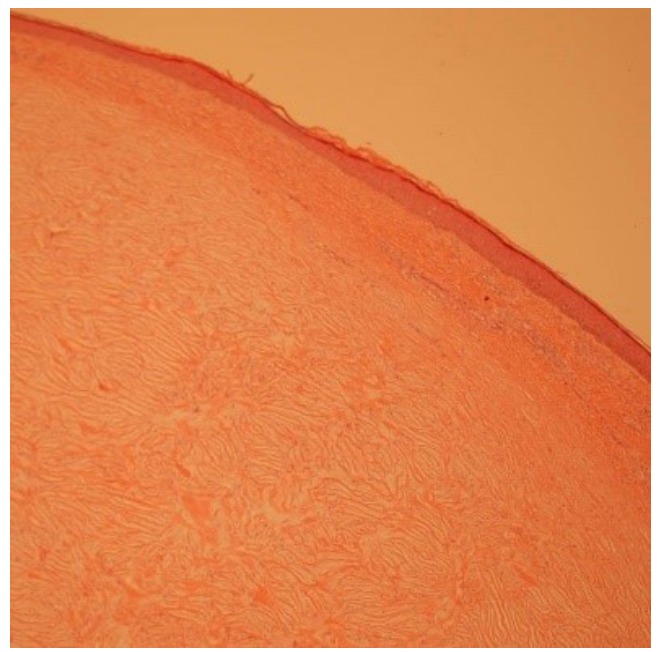

Fig. 3. Histopathologic examination shows a well-defined, hypocellular intradermal fibrotic nodule $(\mathrm{H} \& \mathrm{E}, \times 10)$.

Histopathologically, the lesion showed a well-defined, hypocellular intradermal fibrotic nodule (Fig. 3). It was negative for CD 34, smooth muscle actin, $\beta$-catenin and showed abundant, dense hyalinized collagen bundles (Fig. 4). The most central area had a storiform arrangement intermixed with paucicellular dense collagen bundle that were separated by prominent clefts and it was consistent with sclerotic fibroma (Fig. 5).

\section{DISCUSSION}

Sclerotic fibromas were first reported in 1972 by Weary et al. [1] as multiple tumors in the tongue of patients with Cowden's dis-

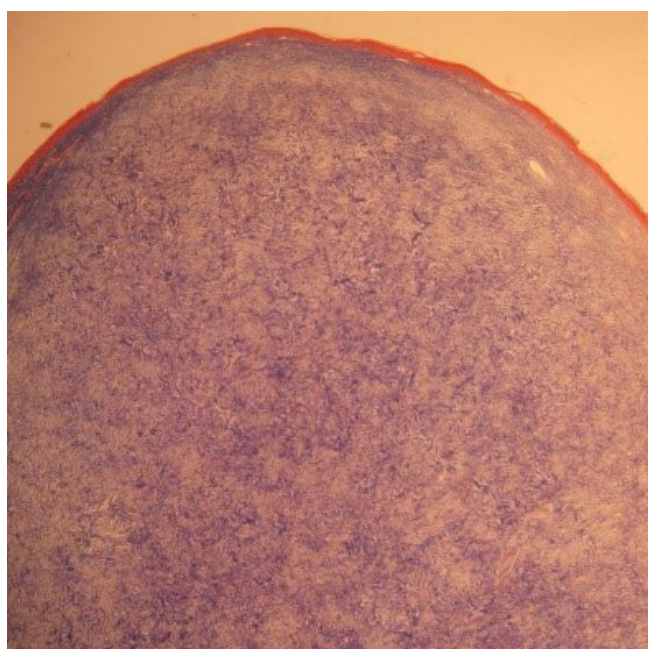

Fig. 4. Immunohistopathologic examination shows abundant, dense hyalinized collagen bundles (trichrome stain, $\times 10$ ).

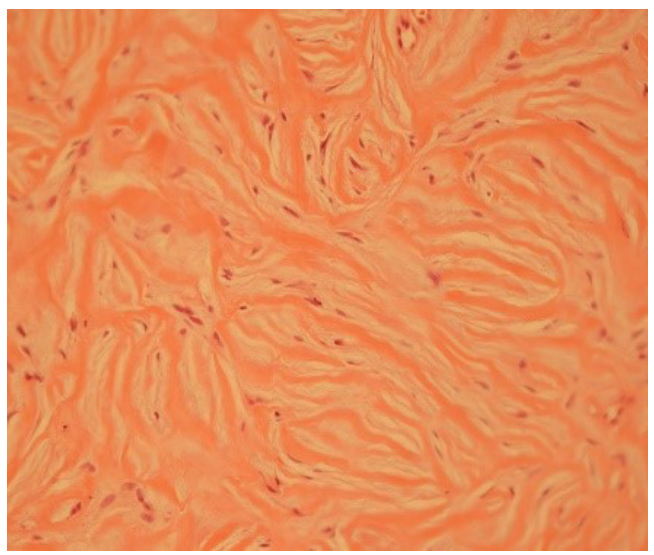

Fig. 5. Storiform patterns of collagenous bundle that were separated by prominent clefts $(\mathrm{H} \& \mathrm{E}, \times 300)$.

ease. In 1989, Rapini and Golitz [2] reported 11 cases of similar sclerotic fibromas in patients without Cowden's disease and were called solitary sclerotic fibroma. The mean patient age was 40 years with a range of 7 to 62 . There was no preferential location; however, five of 11 lesions were located in the head and neck region. The lesion was more common in females (8 of 11). The average lesion size was $5.5 \mathrm{~mm}$ with a range of 2 to $9 \mathrm{~mm}$. Since our case did not satisfy the diagnostic criteria of Cowden's disease, the patient was diagnosed with a solitary sclerotic fibroma. Clinically, solitary sclerotic fibroma presents as asymptomatic, well-defined, skin-colored, round to ovoid nodules. Because the clinical findings were similar to a keloid scar, it was difficult to confirm the diagnosis. Therefore, it is important to differentiate between sclerotic fibroma and keloid scar to determine the treatment model for prevention of recurrence after surgery.

Sclerotic fibroma is commonly found on the face and limbs 
Table 1. Differential diagnosis between sclerotic fibroma and keloid scar

\begin{tabular}{lll}
\hline & & \multicolumn{1}{c}{ Sclerotic fibroma } \\
\hline Preferred site & Face, extremity, trunk & Keloid scar \\
Presentation & Slow-growing flesh-colored papule or nodule with firm, yellow-tan surface & Mass like lesion or scar that grows beyond original wound \\
Prognosis & Excellent, rarely local recur & Persistence and recurrence are common \\
Pathology & Thin collagen bundles in a storiform pattern & Thick collagen bundles in a ripple-like pattern \\
& Prominent clefts between collagen bundles & No clefts \\
& Usually hypocellular & Usually hypercellular \\
\hline
\end{tabular}

but it also appears on the scalp, trunk, and oral mucosa [3,4]. It presents as slow-growing flesh-colored papule or nodule and has an excellent prognosis.

Alternatively, the common sites of keloid scars are the earlobe, presternal, and deltoid regions. They often have a definite trauma history. It presents as a scar or mass that grows beyond original wound and recurrence are relatively common. Therefore, surgical excision alone has an excessively high recurrence rate. Radiation therapies have been known to reduce the recurrence rate of keloid scar $[5,6]$.

Sclerotic fibroma should be considered in the differential diagnosis with keloid scar and histopathology is the most reliable method to confirm the diagnosis. A sclerotic fibroma shows paucicellular dense and relatively thin collagenous bundles that are separated by prominent clefts arranged in a storiform pattern, while a keloid scar show dense, broad, haphazardly arranged thick collagen bundles which exhibits a ripple-like arrangement (Table 1).

In summary, sclerotic fibroma is a relatively rare soft tissue tumor of the skin that shows characteristic histopathological findings but nonspecific clinical findings. Although the clinical appearance is indistinct, the histopathological characteristics are firmly established and easily recognized. Surgeons should include sclerotic fibroma in the differential diagnosis of keloid scar and histopathology is needed to confirm the diagnosis.

\section{NOTES}

\section{Conflict of interest}

No potential conflict of interest relevant to this article was reported.

\section{Ethical approval}

The study was approved by the Institutional Review Board of Bundang Jesaeng Hospital (IRB No. 2020-06-007) and per- formed in accordance with the principles of the Declaration of Helsinki. Written informed consent was obtained.

\section{Patient consent}

The patient provided written informed consent for the publication and the use of his images.

\section{ORCID}

Ji Hoon Kim

https://orcid.org/0000-0003-0082-6315

Chi Ho Shin

https://orcid.org/0000-0002-7418-1575

Dong Chul Kim

https://orcid.org/0000-0003-3244-7918

So Ya Paik

https://orcid.org/0000-0003-4707-574X

Chong Kun Lee

\section{REFERENCES}

1. Weary PE, Gorlin RJ, Gentry WC Jr, Comer JE, Greer KE. Multiple hamartoma syndrome (Cowden's disease). Arch Dermatol 1972;106:682-90.

2. Rapini RP, Golitz LE. Sclerotic fibromas of the skin. J Am Acad Dermatol 1989;20(2 Pt 1):266-71.

3. Herrera Sanchez M, Suanez Fernandez R, del Cerro Heredero M, Rueda Gomez-Calcerrada M, Vigaray Conde J, Sanchez Yus E. Sclerotic fibroma. Dermatology 1998;196:429-30.

4. Ebadian M, Citarella L, Collins D, Diaz-Cano S, Pozo-Garcia L. Dermoscopy of a solitary storiform collagenoma. Dermatol Pract Concept 2018;8:120-2.

5. Wolfram D, Tzankov A, Pulzl P, Piza-Katzer H. Hypertrophic scars and keloids: a review of their pathophysiology, risk factors, and therapeutic management. Dermatol Surg 2009;35: 171-81.

6. Lee SY, Park J. Postoperative electron beam radiotherapy for keloids: treatment outcome and factors associated with occurrence and recurrence. Ann Dermatol 2015;27:53-8. 